\title{
Circularly Polarized MIMO Antenna Using F-Shaped Mirrored Structure
}

\author{
Pavithra $\mathrm{S}^{\mathrm{a}, 1}$ and AmeeliaRoseline $\mathrm{A}^{\mathrm{b}}$ \\ ${ }^{a} P G$ scholar ,Dept of ECE, Panimalar Engineering College, Chennai \\ ${ }^{\mathrm{b}}$ Professor, Dept of ECE, Panimalar Engineering College, Chennai
}

\begin{abstract}
In MIMO(multiple input multiple output )system,antenna performance are degraded by mutual coupling hence to overcome this we go for circular polarization. In this paper we use planar,circularly polarized MIMO patch with three grounded stubs, F-shaped mirrored structure to achieve same time isolation \&matching with offset feeding between two patches for circularly polarization. The elements of antenna are closely packed with $0.06 \lambda 0$ of edge to edge distance at 2.5 GHZ frequency. The proposed antenna will results the impedance matching $\mathrm{S} 11<$ $-10 \mathrm{~dB}$ and high isolation of $\mathrm{S} 12<-20 \mathrm{~dB}$.
\end{abstract}

Keywords.CircularPolarization-CP, axialratio-AR, envelope correlation coefficient - ECC.

\section{Introduction}

MIMO (multiple input multiple output) antenna is a wireless communication technology which is used for both transmission and reception.In this paper we used circularly polarized (CP)MIMO antenna which will operate in $2.5 \mathrm{GHz}$ for WLAN(IEEE $802.11 \mathrm{~b} / \mathrm{g} / \mathrm{n} / \mathrm{a}$ ) applications. The main advantage for going Circularly polarized MIMO antenna is for Line of sight (LOS, point to point)\& multipath (broadcast)communication. Rectangular patch is used to design antenna and polarization mismatches are reduced in transmitter and receiver side due to CP.Rogers substrate( RO4350B) is a dielectric constant which laminates and control losses for utilizing same processing as standard method for epoxy/glass.It is an active device for designing RF systems.It is also a low cost substrate like FR-4.Radiation pattern is the graphical representation of radiation charcteristics of antenna element and it states that power radiated in antenna is the funtion of direction away from the antenna.Dimensional stability is very good in rogers substrate. We can also minimize electrical noise in thissubstrate.

\footnotetext{
${ }^{1}$ Pavithra.S, PG Scholar Dept of ECE, PanimalarEngineering College, Chennai, India; E-mail: pavithrasrinivasan006@gmail.com.
} 


\section{Related works}

Recently, MIMO technology has been increasing the link capacity mainly in multipath environments [1].Nowadays all wireless modern applications like LTE\&Wi-Fi (IEEE 802.11ac, 802.11n) systems required MIMO systems[2]. polarization mismatches are reduced due to Circularly polarized antenna (CP)makes their own orientation in transmitter and receiver side[3].The study says that Circularly polarized MIMO antenna are linearly polarized (LP) [4]. line of sight (LOS, point to point)\& multipath (broadcast)in both cases are investigated by camparison of diversity gain, channel capacity and ECC.For increasing radiation interaction antennas should be closely packet and coupled each other. some techniques to reduce mutual coupling are microstrip stubs [5],defected ground structure [DGS] [6], [7], electromagnetic band gap EBG[8], [9], parasitic elements[10],shorting pin [11], [12], etc.Few CP MIMO antennas are reported as high gain [13], [14], planar[15],[16] wideband [17],[18]applications.Simple feeding are used in dielectric substrate with polarization diversity. For planar applications 3D construction are not used. By offset feeding structure patch antenna is designed and analysed for cp operation[19]but it can be used only for SISO applications. Indications of above discussion states that realization of MIMO CP antenna is challenge for simple feeding \& edge-to-edge structure separation.

\section{Proposed Design}

The design of antenna is taken from the paper[20].The modification what is done from that paper[21] is the top layer of the antenna design is taken and achieved those values by simulation in ADS software and simplifed the circuit design. By simplification, the antenna design size is reduced and cost for implementation is less .In this proposed paper compact MIMO CP antenna and planar antenna is used[22]. Rogers substrate(RO4350B) is used to design antenna. In circular polarization,high isolation is adopted in F-shaped mirrored structure \& Three grounded stubs with simple feeding. The elements of antenna were closely packed with distance $0.06 \lambda_{0}$ of edge to edge at $2.5 \mathrm{GHZ}$ frequency. The antenna will results the impedance matching $\mathrm{S}_{11}<-10 \mathrm{~dB}$ and high isolation of $\mathrm{S}_{12}<-20 \mathrm{~dB}$ in simulation.

$$
\begin{gathered}
\mathrm{A}=\frac{z O}{60} \sqrt{\frac{\varepsilon r+1}{2}}+\frac{\varepsilon r-1}{\varepsilon r+1}\left(0.23+\frac{0.11}{\varepsilon r}\right) \\
\varepsilon_{e f f}=\frac{\varepsilon r+1}{2}+\frac{\varepsilon r-1}{2}\left(1+12 \frac{h}{w}\right)-1 / 2(2) \\
\mathrm{L}=\frac{c}{4 f \sqrt{\varepsilon_{e f f}}}(3) \\
\frac{w}{d}=\left\{\frac{8 e^{A}}{e^{2 A}-2}\right.
\end{gathered}
$$




\section{Proposed designs and implementations}

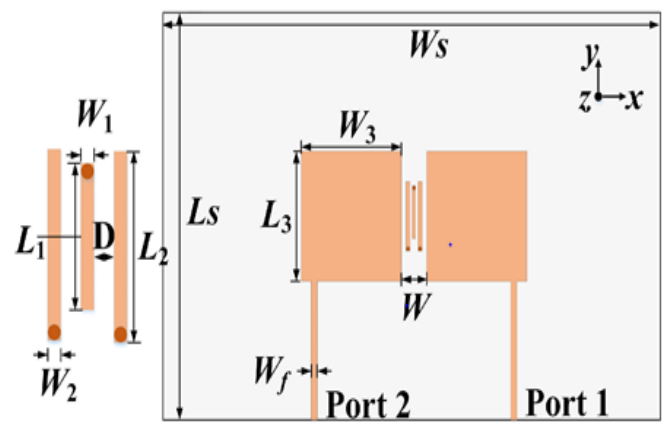

Figure 1. Antenna design[21]

\begin{tabular}{|l|l|}
\hline parameters & $\begin{array}{l}\text { Measure } \\
\text { ments } \\
(\mathbf{m m})\end{array}$ \\
\hline $\mathrm{R}$ & $50 \Omega$ \\
$\mathrm{W}$ & 1.8 \\
$\varepsilon_{\mathrm{r}}$ & 3.66 \\
$\mathrm{~W}_{\mathrm{s}} * \mathrm{~L}_{\mathrm{s}}$ & $150 * 100$ \\
$\mathrm{~h}$ & 0.8 \\
$\mathrm{~L}_{1}$ & 12.903 \\
$\mathrm{~W}_{1}$ & 0.9614 \\
$\mathrm{~W}_{2}$ & 1.2626 \\
$\mathrm{~L}_{2}$ & 16.951 \\
$\mathrm{D}$ & 0.71 \\
$\mathrm{~L}_{\mathrm{s}}$ & 100 \\
$\mathrm{~L}_{3}$ & 31.878 \\
$\mathrm{~W}_{\mathrm{f}}$ & 1.8 \\
$\mathrm{~W}$ & 7.65 \\
$\mathrm{~W}_{\mathrm{s}}$ & 150 \\
$\mathrm{~W}_{3}$ & 30.355 \\
\hline
\end{tabular}

Table 1. Proposed values of antenna design

The fig. 1 is says that Rectangular patch antenna is closely packed in the top layer of antenna and three grounded stubs are placed in between that. Ground plane is placed in bottom layer with mirrored F-shaped structure. Feed of patch is $50 \mathrm{ohms}$ and thickness is $0.8 \mathrm{~mm}$, width is $1.8 \mathrm{~mm}(150 \mathrm{~mm} \times 100 \mathrm{~mm})$ and dielectric constant is 3.66 . RO4350B is Rogers substrateisused.Dielectric constant $\varepsilon r=3.66$, loss tangent of 0.0037 and the thickness $\mathrm{h}=0.8 \mathrm{~mm}$. Table1says that Proposed designs of antenna values $\mathrm{W}_{1}=0.9614, \mathrm{~L}_{1}=12.903, \mathrm{~L}_{3}=31.878, \mathrm{~L}_{2}=16.951, \mathrm{~W}=7.65, \mathrm{~L}_{4}=50, \mathrm{~W}_{\mathrm{f}}=1.8, \mathrm{~L}_{5}=40$, $\mathrm{L}_{6}=32, \mathrm{~W}_{2}=1.2626, \mathrm{~W}_{3}=30.355, \mathrm{~W}_{6}=9, \mathrm{~W} 4=3, \mathrm{~W}_{5}=5.25, \mathrm{Ws}_{\mathrm{s}}=150, \mathrm{Ls}=100, \mathrm{D}=0.71$, $\mathrm{L}_{\mathrm{f}}=34.06$.

Table 2. Comparison with before CP MIMO antennas

\begin{tabular}{|c|c|c|c|c|c|c|}
\hline REFERENCE & $\begin{array}{c}\text { SPACING } \\
(\text { LAMDA })\end{array}$ & S21 $(\mathrm{dB})$ & $\begin{array}{c}\text { Isolation } \\
\text { Technique }\end{array}$ & $\begin{array}{c}\text { Feeding+ } \\
\text { Complexity }\end{array}$ & $\begin{array}{l}\text { Antenna } \\
\text { height(mm) }\end{array}$ & $\begin{array}{l}\text { Maximum } \\
\text { gain(dBi) }\end{array}$ \\
\hline$[14]$ & 0.19 & -25 & DGS & $\begin{array}{l}\text { Microstrip+ } \\
\text { Simple }\end{array}$ & 7.6 & 4.7 \\
\hline$[18]$ & 0.3 & -25 & PE & $\begin{array}{l}\text { Microstrip+ } \\
\text { Simple }\end{array}$ & N.G. & 4 \\
\hline$[19]$ & 0.5 & -30 & PE+DRA & $\begin{array}{l}\text { Microstrip+ } \\
\text { Simple }\end{array}$ & 26.1 & 5.2 \\
\hline$[20]$ & $>0.6$ & -30 & N.G. & $\begin{array}{l}\text { Coaxial+ } \\
\text { Complex }\end{array}$ & 1.6 & 1.5 \\
\hline$[21]$ & N.G. & -19 & $\begin{array}{c}\text { Orthogonal } \\
\text { modes }\end{array}$ & $\begin{array}{l}\text { Coaxial+ } \\
\text { Simple }\end{array}$ & 0.127 & N.G. \\
\hline Proposed & 0.06 & -17.266 & CP & $\begin{array}{l}\text { Microstrip+ } \\
\text { Simple }\end{array}$ & 0.8 & 6.1 \\
\hline
\end{tabular}




\section{Simulated design and Results}

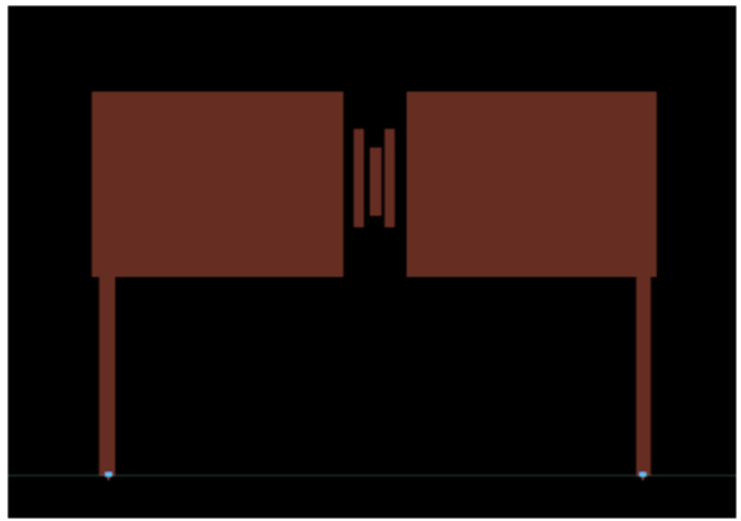

Figure 2. Layout of antenna

The antenna was designed in ADS software and the material used to design antenna is rogers substrate(RO4350B), the dielectric constant is 3.66 and the thickness is $0.8 \mathrm{~mm}$.

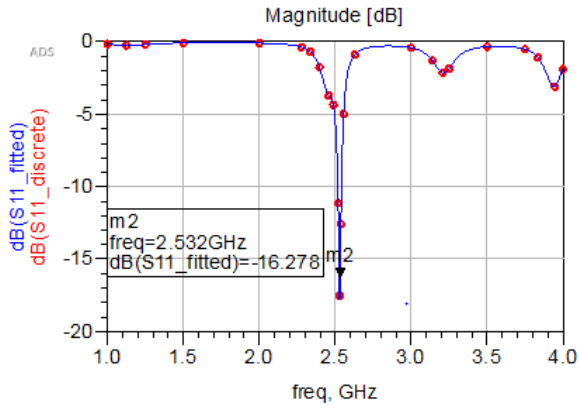

Figure 3. $\mathrm{S}_{11}$ simulation for $2.5 \mathrm{GHz}$
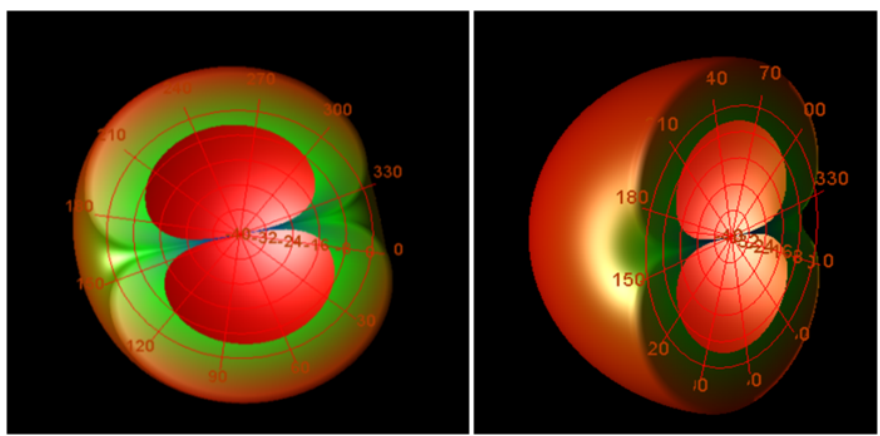

Figure 5. Radiation pattern of antenna
Magnitude $[\mathrm{dB}]$

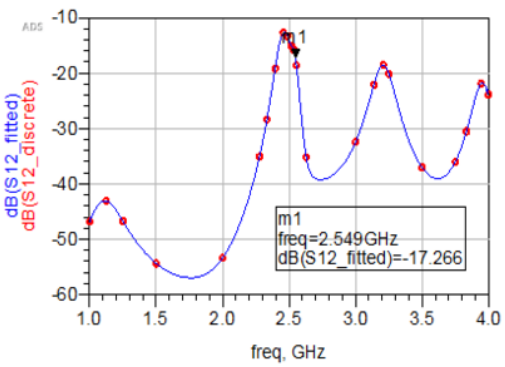

Figure 4. $S_{21}$ simulation for $2.5 \mathrm{GHz}$ 


\section{Conclusion}

In this paper, MIMO CP(circular polarization) antenna and planar antenna is used. In circular polarization, high isolation is adopted in F-shaped mirrored structure\& Three grounded stubs with simple feeding. The elements of antenna were closely packed withdistance $0.06 \lambda_{0}$ of edge to edge at $2.4 \mathrm{GHZ}$ frequency. The resultedimpedance matching antenna values for $S_{11}$ values is $-16.278 \mathrm{~dB}$ and $S_{21}$ value is $-17.266 \mathrm{~dB}$ was obtained in simulation. Thus design of antenna in $2.5 \mathrm{GHz}$ band $802.11 \mathrm{n}$ for Wi-Fi applications is achieved.

\section{References}

[1] R. Murch and K. Letaief, Antenna systems for broadband wireless access. IEEE Commun. Mag., vol. 40, no. 4, pp. 76-83, Apr. 2002.

[2] E. G. Larsson, O. Edfors, F. Tufvesson, and T. L. Marzetta, Massive MIMO for next generation wireless systems. IEEE Commun. Mag., vol. 52, no. 2, pp. 186-195, Feb. 2014.

[3] Y. Ding and K. Wa Leung, Dual-band circularly polarized dual-slot antenna with a dielectric cover. IEEE Trans. Antennas Propag., vol. 57, no. 12, pp. 3757-3764, Dec. 2009.

[4] F. A. Dicandia, S. Genovesi, and A. Monorchio, Analysis of the performance enhancement of MIMO systems employing circular polarization . IEEE Trans. Antennas Propag., vol. 65, no. 9, pp. 4824-4835, Sep. 2017.

[5] A. A. Ibrahim, M. A. Abdalla, A. B. Abdel-Rahman, and H. F. A. Hamed, Compact MIMO antenna with optimized mutual coupling reduction using DGS. Int. J. Microw. Wireless Technol., vol. 6, no. 2, pp. 173-180, Apr. 2014.

[6] S. Kamal and A. A. Chaudhari,Printed meander line MIMO antenna integrated with air gap, DGS AND RIS: A low mutual coupling design for LTE applications.Prog. Electromagn. Res. C, vol. 71, pp. 149159, 2017.

[7] F. Yang and Y. Rahmat-Samii, Microstrip antennas integrated with electromagnetic band-gap (EBG) structures: A low mutual coupling design for array applications. IEEE Trans. Antennas Propag., vol. 51, no. 10, pp. 2936-2946, Oct. 2003.

[8] E. Rajo-Iglesias, O. Quevedo-Teruel, and L. Inclan-Sanchez, Mutual coupling reduction in patch antenna arrays by using a planar EBG structure and a multilayer dielectric substrate. IEEE Trans. Antennas Propag., vol. 56, no. 6, pp. 1648-1655, Jun. 2008.

[9] L. Liu, S. W. Cheung, and T. I. Yuk, Compact MIMO antenna for portable devices in UWB applications. IEEE Trans. Antennas Propag., vol. 61, no. 8, pp. 4257-4264, Aug. 2013.

[10] S. Shoaib, I. Shoaib, N. Shoaib, X. Chen, and C. G. Parini, Design and performance study of a dualelement multiband printed monopole antenna array for MIMO terminals. IEEE Antennas Wireless Propag. Lett., vol. 13, pp. 329-332, 2014.

[11] M. U. Khan and M. S. Sharawi, A $2 \times 1$ multiband MIMO antenna system consisting of miniaturized patch elements.Microw. Opt. Technol. Lett., vol. 56, pp. 1371-1375, Jun. 2014.

[12] R. Zaker, Design of a very closely-spaced antenna array with a high reduction of mutual coupling using novel parasitic L-shaped strips.Int. J. RF Microw. Comput. Aided Eng., vol. 28, no. 9, Nov. 2018, Art. no. e21422.

[13] S. Karamzadeh, V. Rafiei, and H. Saygin, PD FPR CP high-gain MIMO antenna. Electron. Lett., vol. 53, no. 17, pp. 1174-1176, 2017.

[14] G. Das, A. Sharma, and R. K. Gangwar .Dielectric resonator based circularly polarized MIMO antenna with polarization diversity.Microw. Opt. Technol. Lett., vol. 60, no. 3, pp. 685-693, 2018.

[15] Nasimuddin, X. Qing, and Z. N. Chen .A wideband circularly polarized antenna for low mutual coupling Ka-band phased arrays .in Proc. IEEE Region 10 Conf. (TENCON), Nov. 2016, pp. 10651067.

[16] I. Adam, M. N. M. Yasin, N. Ramli, M. Jusoh, H. A. Rahim, T. B. A. Latef, T. F. T. M. N. Izam, and T. Sabapathy .Mutual coupling reduction of a wideband circularly polarized microstrip MIMO antenna. IEEE Access, vol. 7, pp. 97838-97845, 2019.

[17] J. Iqbal, U. Illahi, M. I. Sulaiman, M. M. Alam, M. M. Suud, and M. N. M. Yasin .Mutual coupling reduction using hybrid technique in wideband circularly polarized MIMO antenna for WiMAXapplications . IEEE Access, vol. 7, pp. 40951-40958, 2019. 
[18] T.-D. Yeo, S. C. Chae, B. Ahn, and J.-W. Yu, Rotational circularly polarized array antenna for mutual coupling reduction .in Proc. Int. Symp. Antennas Propag. (ISAP), Oct. 2017, pp. 1-2.

[19] M. K. A. Nayan, M. F. Jamlos, and M. A. Jamlos.Mimo circular polarization array antenna with dual coupled $90^{\circ}$ phased shift for point-to-point application.Microw. Opt. Technol. Lett., vol. 57, no. 4, pp. 809-814, Apr. 2015.

[20] Z. Yang and K. F. Warnick, Analysis and design of intrinsically dual circular polarized microstrip antennas using an equivalent circuit model and jones matrix formulation. IEEE Trans. Antennas Propag., vol. 64, no. 9, pp. 3858-3868, Sep. 2016.

[21] Muhammad yasirjamal, Kwan lawerenceyeung.Isolation Enhancement of Closely Packed Dual Circularly Polarized MIMO Antenna Using Hybrid Technique.

[22] M.Messiah Josephine, A.AmeeliaRoseline.Radio Resource Management ForFemto Cell Wireless Network Based On MIMO-OFDM Communication. International Journal of Innovative Technology and Exploring (IJITEE) ISSN:2278-3075,volume-9 Issue-1S,November 2019. 